\title{
Design of Strategic Management System for Northern Border University using Unified Modeling Language
}

\author{
Shahrin Azuan Nazeer \\ Department of Computer Science, Faculty of Science \\ Northern Border University \\ Arar, Saudi Arabia
}

\begin{abstract}
All organizations engage in the strategy management process either formally or informally. Strategy management is used to refer to the entire scope of strategicdecision making activity in an organization to ensure its continuous success. Hence, a strategic management system is viewed as an important tool for strategy management. Northern Border University started to initiate its first five-year strategy plan for the year 1435-1439H (2013-2018). However, the strategy plan is managed without having a strategic management system. Thus, the university has a fundamental disconnect between the formulation of the strategy and the execution of that strategy into useful action. There is no integration between the strategy formulation and implementation which are treated separately instead of as an integrated system. Therefore, it is difficult for the university to translate their strategies into operational objectives, processes and activities. This paper presents the design process of the strategic management system for the university, whose main purpose is to manage the university's strategy plan throughout its life cycle. The design of the strategic management system is based on object-oriented approach using Unified Modeling Language. The system will be used to formulate, implement, monitor and control appropriate university's strategy plan to support on strategic-decision making for the university. The solution will thus contribute to the improvement of the university's performance.
\end{abstract}

Keywords-Strategy management; strategic management system; object-oriented analysis and design; unified modeling language

\section{INTRODUCTION}

Strategy management is used to refer to the entire scope of strategic-decision making activity in an organization. Basically, strategy management includes strategy planning and strategy implementation. Strategy planning consists of formulating strategies from which overall plans for implementing the strategy are developed. Strategy implementation consists of ensuring that the chosen strategy is being implemented properly and that it is producing the desired results. Strategies are the means by which long-term objectives will be achieved. The role of strategy is to identify the general approaches that the organization utilized to achieve its organizational objectives. Therefore, the choice of strategy is so central to the study and understanding of strategy management. The success of an organization is generally dependent upon the strategy management and organizational abilities of the management.

For the last two decades, strategy planning has been broadly regarded as the most important component of the strategic management process in the sense that it is more important than strategy implementation [15, 25]. The deficiency in strategy implementation creates a deadly spiral of two mutually enforcing factors poor planning and poor implementation [7]. Despite the perceived significance of strategy implementation, inadequate research has been carried out on the strategy management process component. In [22], Noble pointed out that the deep and cohesive bodies of strategy implementation research still do not exist. In fact, the strategy implementation is viewed as the most difficult component of the strategic management process [2, 10, 14, 26, 27], and the bulk of good strategy planning has failed in its implementation [1, 3, 4, 14, 17, 21]. Ramaseshan, Ishak, and Rabbanee [25] stated that there exist a small number of guidelines for successful strategy implementation. Research highlighted that the capability to implement strategy is viewed as very important in order to achieve superior business performance [11, 16, 21]. Parnell [24] also argues that strategy formulation only produces superior performance for an organization when it is successfully implemented. Today, strategy planning and implementation have become the key requirements for business performance $[12,20]$.

Strategy plan is one of the main factors that contribute to the success of any institution with different goals. It brings together the potentials of human, financial and moral resources to achieve objectives and aspirations with the support of a welldefined plan that can be accomplished according to a specific timeframe. Strategy plan is a means to achieve strategy aims and objectives, associated with the progress and development of the institution. It also represents a road map that serves as a guide to achieve the desired objective, in particular through proper planning, guidance and control in addition to considerations of long standing problems and issues.

Northern Border University (NBU) was established in 2007. The university started to initiate its first strategy plan for the year 1435-1439H (2013-2018). The strategy plan is created to be in line with the aims of the university, notably achieving a comprehensive development in both academic and institutional levels in order to improve its outcomes and services to meet both national and international quality assurance standards. The plan also aims to serve the university comprehensive development plans as well as meets the demands of the community and labor market. The strategy plan of the university has basic information about the Northern Borders province such as its characteristics and popular activities. It also provides information indicating the current 
status of the university and the Northern Borders region, notably general information about the university location and its branches in relation to other universities in the kingdom. The plan further involves an analysis of the indices of the field studies associated with the university, which in turn includes distinctive executive programs that are at the same time compatible with all tracks and programs of the university education future plan. All are considered to be within the framework of the five-year plan and the comprehensive development policies of the kingdom.

However, the strategy plan is managed without having a proper application system. Thus, the university has a fundamental disconnect between the formulation of the strategy and the execution of that strategy into useful action. There is no integration between the strategy formulation and implementation which are treated separately instead of as an integrated system. Therefore, it is difficult for the university to translate their strategies into operational objectives, processes and activities. An important reason for this is that the university is lacking an effective strategic management system with which they can realize their strategic and operational objectives. An effective strategic management system is absent that allows management to manage strategy planning and execution in an integrated way. Thus, a strategic management system is found vital to manage and support NBU's strategy management to formulate, implement, monitor and control appropriate university's strategy plan to support on strategicdecision making for the university.

The purpose of the paper is to present the analysis and design of a proposed strategic management application system for NBU based on object-oriented approach using Unified Modeling Language (UML). The paper is organized as follows. Section I provides the introduction of the paper. Section II discusses on the strategy management system. Section III describes the methodology used to analyze and design the strategic management application system. Section IV explains on the design of the strategic management application system for NBU, and finally Section V provides the conclusion of the paper.

\section{STRATEGIC MANAGEMENT SYSTEM}

Strategic management system (SMS) is a management system that aligns and integrates the strategy planning and strategy implementation to monitor and control the strategy plan and its execution for organizations to achieve its strategy plan and objectives. SMS consists of a planning, implementation and control cycle. Planning refers to strategic planning which is the formulation of the strategy, the translation of the strategy into strategic objectives. Implementation refers to the development of an implementation plan with operational objectives, processes, and activities. Control refers to strategy execution which is the monitoring of the progress of the execution and the adjustment of the strategy or its execution.

Various researches on strategic management system have been conducted for the last four decades $[5,6,8,9,13,18,19$, 23, 28]. Ghymn and Kings [13] presented a systems design methodology which implements five basic criteria for the design of a strategic planning Management Information
System. The methodology uses discriminant analyses of the perceived importance to managers of various categories of strategic information to delineate the most significant information requirements of various managerial groups.

Cotterill [9] conducted a study to facilitate research on strategic management information systems (SMIS) by elaborating and using example from food system to illustrate the design and impact of SMIS.

Bungay and Goold [6] described the development and implementation of a strategic control process for the long-term planning by building long-term thinking into day-to-day operations where the strategic controls are considered as nonfinancial performance measures which are of particular value in a diversified company in controlling, monitoring and guiding the development of operating units.

Lanser [19] proposed a design of a strategic information system to assist executive and management staff make effective customer-focused program and service decisions, and implemented a customer driven organizational model called the "System of Education" to improve the effectiveness and competitiveness of communication and decision-making at Lakeshore Technical College.

Karim [18] explores the extent to which management information systems (MIS) implemented to make successful decisions at two selected financial organizations. He adapted the quantitative research design to examine whether the selected financial institutions vary as to the use of MIS on decision making for strategic and tactical planning purposes. The results showed that MIS was primarily used to enhance strategic planning in both financial institutions. The regression analysis revealed that Tactical planning is found to have no effect on Decision Making, while Strategic planning has a clear effect on the Decision Making Effectiveness in both organizations.

Wanjohi [28] conducted a study to identify and examine the relationship between the Strategic Control System (SCS) application and financial performance of Bamburi Cement Limited, Kenya using the Pearson's product moment correlation coefficient and regression analysis.

Bento and White [5] proposes and tests a model to explain the impact on business results of Strategic Performance Measurement Systems (SPMS). The SPMS information technology (IT) variables, which include both technical characteristics and technical outcomes, affect business results. IT and system variables are affected by organizational variables related to information processing capabilities and requirements. System effectiveness and Internet usage were the two IT variables found to have the most impact on business results. The system design had a significant role in determining all IT variables that had an impact on business results.

O'Sullivan [23] presented a case study on the implementing a Strategic Planning and Management System at a Private Higher Education Institution in the Middle East based on balanced score card. The balance score card is used as a means for measuring performance and driving strategy. The results of the study reveal that frequency change in strategy is a major factor leading to the difficulty to implement balance score card, 
which in turn suggests that local culture and local organization culture needs to be considered when implementing new planning and measurement system.

In term of strategic management application system, most of the organizations prefer to build their own strategic management application system in-house, to out-source the software development to companies or consultants, or to procure commercially available off-the-shelf strategy management software products such as StrategyBlocks, Cascade, ClearPoint, OnStrategy, Shibumi, FIBRES, CAMMsStrategy, i-nexus, Khorus, SAP Strategy Management, StrategyExecution or Envisio.

\section{UNIFIED MODELING LANGUAGE}

There are two approaches for the development of information system which are structured and object oriented approaches. The structured approach uses three techniques basically logical data modeling, data flow modeling and entity behavior modeling. Meanwhile, the object-oriented (OO) approach uses UML. In this research work, the latter approach using UML is used. UML is a language which provides a comprehensive notation for communicating the requirements, architecture, implementation, deployment, and states of a system. It is a modeling language that is used to provide a standard way to visualize the design of a system. The objective of UML is to provide a common vocabulary of object oriented terms and diagramming techniques that are rich enough to model any systems development project from analysis through implementation.

Although there are various diagramming techniques used in UML, but the most common diagrams used for software engineering are use case diagram, class diagram, and sequence diagram. Use Case diagram is used to gather the requirements of a system including internal and external influences by capture the dynamic behavior of a system. It gathers the functionalities as use case, identifying the actors, and set the relationships among the use cases and actors. Class diagram is a static structural diagram which represents the static view of a system. It is used to describe the attributes and operations of a class and also the constraints imposed on the system. The class diagram shows a collection of classes, interfaces, associations, collaborations, and constraints. Sequence diagram is used to model the interactions between objects in a single use case. It shows the interaction among a set of objects participated in a collaboration, and the messages that they send to each other in a chronological order.

OO system analysis and design focuses on three aspects which are object, analysis and design. Concepts in $\mathrm{OO}$ system include classes, objects, methods, encapsulation, inheritance, and dynamic binding. The concept of object contains both data and process which represents the real world. With the concept of encapsulation, an object hides its data and allows only the object's method to access its data which makes the system more flexible and easier to maintain if an object's data structure is changed. OO analysis (OOA) looks at the functional of the system resulted in conceptual model while the OO design (OOD) looks at how the system works covers both functional and non-functional. OOA resulted in functional model, structural model and behavioral models. At the

Deanship of Scientific Research, Northern Border University, Arar, Saudi Arabia. analysis phase, functional model describes business processes and how the system interacts with its environment. The structural or conceptual modeling presents the logical organization of data independent from how the data are stored, created, or manipulated so that analysts can focus on the business without being distracted by technical details. The behavioral model describes what internal logic of the processes is without specifying how the processes are to be implemented. At the design phase, the structural model is updated with how the data will be stored in databases and files. In other words, OOA analysis and OOD uses the same diagramming techniques, the difference is that in design phase the system environment details are added and refined problem domain information to increase the likelihood of successfully delivering a system.

\section{DESIGN OF STRATEGIC MANAGEMENT SySTEM}

The proposed SMS comprises of three (3) modules which are Strategy Planning module, Strategy Implementation module, and Strategy Monitoring module. The functionalities of the proposed SMS is depicted in Fig. 1. The purpose of Strategy Planning module is to manage the strategy plan information which includes vision, mission, objectives and strategies. The functions of the Strategy Planning module are to manage strategy plan which includes maintaining strategy plan, objective, and strategy, and to generate reports. The purpose of Strategy Implementation module is to manage the strategy implementation plan, project plan, and project performance. The functions of Strategy Implementation Plan module are to manage strategy implementation plan which includes maintaining implementation plan, program, and project, to manage project plan which includes maintaining project plan, project information, and project performance, and to generate reports. The purpose of the Strategy Monitoring module is to monitor and evaluate the strategy planning and strategy implementation by providing learning and feed forward for strategy planning, and corrective actions and feedback for strategy implementation. The functions of Strategy Monitoring module are to monitor strategy planning and implementation which includes monitoring strategy plan, strategy implementation plan, project plan, and program and project performance, to evaluate performance of program and project, and to generate reports.

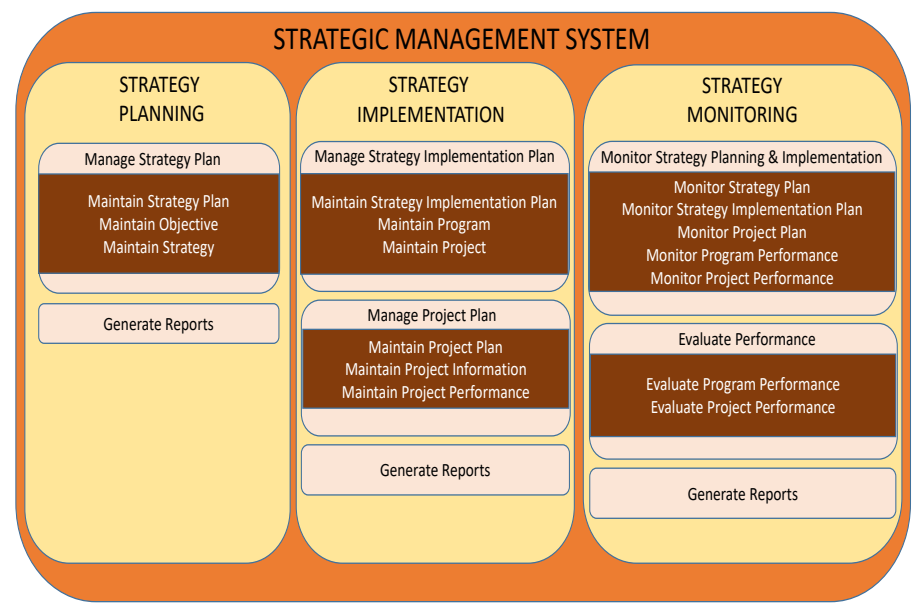

Fig. 1. Functionalities of Strategic Management System 
The design of the SMS is based on object-oriented approach using UML. Basically, three (3) main UML diagrams will be used to design the SMS which are: (i) Use Case diagram, (ii) Class diagram, and (iii) Sequence diagram. Use Case diagram is used to define the main actors and the functionalities of the SMS. Class diagram is used to define the objects or classes with their attributes, operations and relationships for SMS. Sequence diagram is used to define the processes for each of the functionalities of SMS.

\section{A. Use Case Model}

A Use Case model is developed using UML Use Case diagram to define the main actors that will interact with the system and the functionalities each actor would access in the SMS. Four main actors were identified which are the Strategy Planner, the Program Manager, the Project Manager, and the University's Council, where each one should be able to use a wide range of functionalities after authentication and validation. The Use case diagram with the system's main high level functionalities is depicted in Fig. 2.

The Strategy Planner is responsible for formulating the strategy plan. He will initiate the strategy plan, specifically to define the mission, values, and vision, and to formulate the objectives of the organization and the paths to take in order to reach the goals, and generate, evaluate and craft the strategy to achieve the objectives.

The Program Manager and Project Manager are responsible for the implementation of the strategy plan. The Program Manager will be responsible to formulate and manage the implementation plan. He will initiate the implementation plan, specifically to identify the programs and proper projects, and to appoint the Project Manager for the projects.

The Project Manager is responsible to execute and manage the project, after approval by the system, specifically to create the application system, to plan the activities, to identify the project team members, to allocate the necessary resources for each activity, and to update all financial aspects of a project.

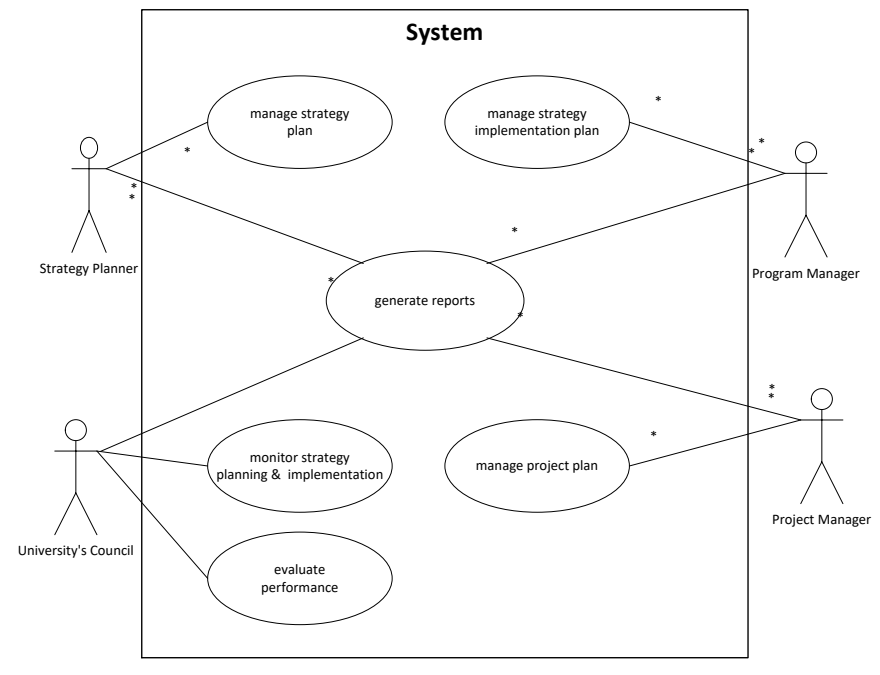

Fig. 2. Use Case Model for Strategic Management System
The University's Council is responsible for Strategy Monitoring and Control by measuring and evaluating performance, monitoring new developments, and initiating corrective adjustment for each project.

The SMS comprises of three (3) modules which are Strategy Planning module, Strategy Implementation module, and Strategy Monitoring module. The use cases for Strategy Planning Module are:

- Manage strategy plan:

a) To maintain strategy plan information: to create and update the vision, mission, value and strategy information.

b) To maintain objective: to create and update long and short term objectives

c) To maintain strategy: to create and update strategy

- Generate reports: to produce strategy progress reports

The use cases for Strategy Implementation Module are:

- Manage Strategy Implementation Plan:

a) To maintain strategy implementation plan: to create and update strategy implementation plan information

b) To maintain program: to create and update program

c) To maintain project: to create and update project

- Manage Project Plan:

a) To maintain project plan: to create and update by project plan information

b) To maintain project information: to create and update project information

c) To maintain project performance: to create and update project performance measures, project progress and project performance

- Generate reports: to produce strategy implementation progress reports and project progress reports

The use cases for Strategy Monitoring Module are:

- Monitor Strategy Planning and Implementation

a) To monitor strategy plan

b) To monitor strategy implementation plan

c) To monitor project plan

d) To monitor program performance

e) To monitor project performance

- Evaluate Performance: to evaluate program and project performance

- Generate reports: to produce program and project review reports

\section{B. Class Model}

A class model is developed using UML class diagram in order to address the identified requirements and to visually describe the problem domain in terms of types of objects (classes) related to each other in different ways for the SMS for NBU. The class diagram presents the abstract information model related to the life cycle of the strategy management. As 
shown in Figure 3, the class model for the SMS for NBU consists of fourteen (14) classes which are Plan class, Mission class, Objective class, Strategy class, Program class, Project class, Bodies class, Activity class, Resource class, Measure class, Outcome class, Progress class, Asset class, and Performance Indicator class.

The Plan class is used to represent the plan of a strategy plan. It has attributes: Plan ID, start date, end date and vision. The operations of Plan Class are to create Plan, update Plan, get Plan, and display Plan. The Plan class has composition relationship with Mission class and Objective class. The Mission class is used to represent the mission for a strategy plan. It has attributes: Mission ID, Plan ID, and mission. The operations of Mission Class are to create Mission, update Mission, and get Mission. The Objective class is used to represent the goals or objectives of a strategy plan. It has attributes: Objective ID, Plan ID and objective. The operations of Goal Class are to create Objective, update Objective, and get Objective. The Objective class has composition relationship with Strategy class. The Strategy class is used to represent the strategy of a strategy plan. It has attributes: Strategy ID, Objective ID and strategy. The operations of Strategy Class are to create Strategy, update Strategy, and get Strategy. The Strategy class has composition relationship with the Program class. The Program class is used to represent the programs of a strategy plan. It has attributes: Program ID, Strategy ID and program. The operations of Program Class are to create Program, update Program, get Program, and display Program. The Program class has composite relationship with Project class.

The Project class is used to represent the project of a strategy plan. It has attributes: Project ID, Program ID, start date, end date, budget, description, status, and remarks. The operations of Project Class are to create Project, update Project, get Project, and display Project. The Project class has composition relationship with Progress class, Bodies class, Measure class, Outcome class, Activity class, Resource class, Asset class, and Performance Indicator class. The Progress class is used to represent the progress of a particular project. It has attributes: Project Progress ID, Project ID, date, status and remarks. The operations of Progress Class are to create Progress, update Progress, get Progress, and display Progress. The Bodies class is used to represent the bodies of a particular project. It has attributes: Body ID, Program ID, body, type and description. The operations of Bodies Class are to create Bodies, update Bodies, and get Bodies. The Measure class is used to represent the performance measure of a particular project. It has attributes: Measure ID, Project ID, measure and type. The operations of Measure Class are to create Measure, update Measure, get Measure, and display Measure. The Outcome class is used to represent the outcome of a particular project. It has attributes: Outcome ID, Project ID and description. The operations of Outcome Class are to create Outcome, update Outcome, and get Outcome. The Activity class is used to represent the activities of a particular project. It has attributes: Activity ID, Project ID, start date, end date, description, status and comment. The operations of Activity Class are to create Activity, update Activity, and get Activity. The Resource class is used to represent the resources of a particular project. It has attributes: Resource ID, Project ID, name, type, role and responsibilities. The operations of Resource Class are to create Resource, update Resource, and get Resource. The Asset class is used to represent the assets of a particular project. It has attributes: Asset ID, Project ID, cost, purchase date, location, status, and remarks. The operations of Asset Class are to create Asset, update Asset, and get Asset. The Performance Indicator class is used to represent the performance indicators of a particular project. It has attributes: Performance Indicator ID, Project ID, description, date, status, and achievement. The operations of Performance Indicator Class are to create Performance Indicator, update Performance Indicator, get Performance Indicator, and display Performance Indicator.

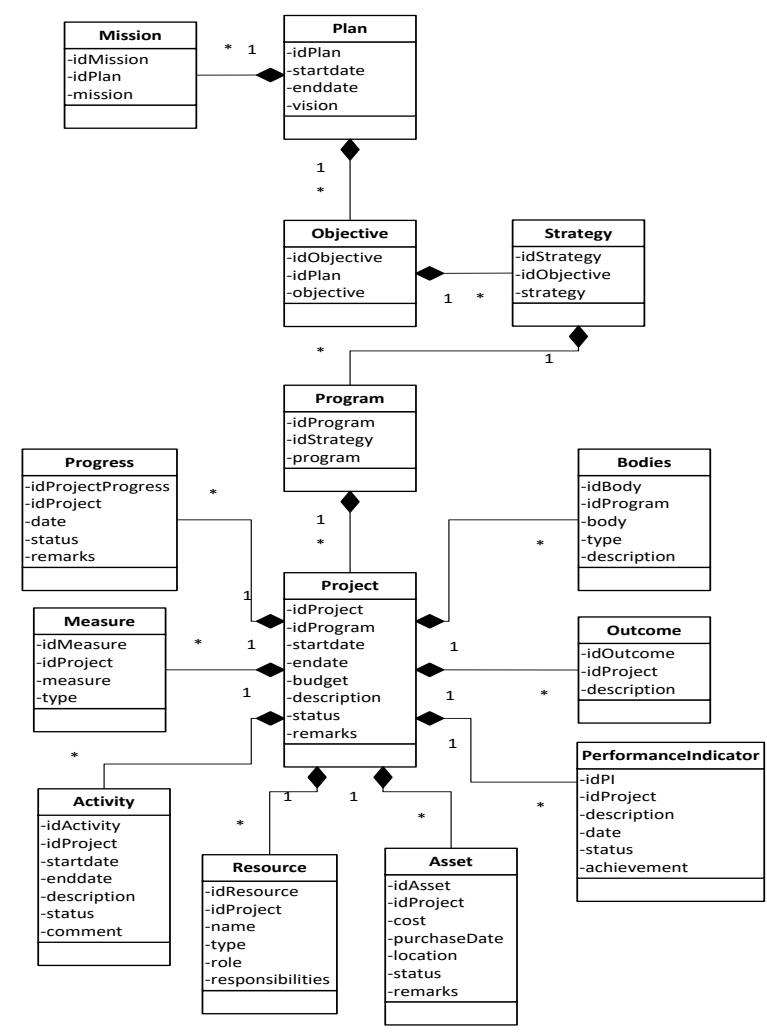

Fig. 3. Class Model for Strategic Management System

A relational database management system (RDBMS) will be used to store data of the SMS. The RDBMS supports referential integrity, providing input check of the uniqueness of primary key. The objects in our design will be converted so they can be stored in a table.

\section{Sequence Diagram}

The sequence diagrams for the SMS consists of manage strategy plan, manage strategy implementation plan, manage project plan, monitor strategy planning and implementation, evaluate performance, and generate reports.

\section{- Manage Strategy Plan}

The Strategy Planner is responsible to manage the strategy plan. The processes to manage strategy plan are to maintain (create or update) the strategy plan, to maintain (add or update) objective, and to maintain (add or update) strategy. As 
depicted in Fig. 4, the manage strategy plan sequence diagram consists of maintain strategy plan, maintain objective, and maintain strategy.

The steps to maintain (create or update) the strategy plan are as follows:

1) Select Create/Update Strategy Plan

2) Display data entry form to create/update strategy plan

3) Fill in the strategy plan information using the data entry form

4) Check and validate the information entered

5) If the data entry is incomplete, return a message "Incomplete data entry form", else proceed to store the data into the database

6) Return data successful stored/updated into the database

7) Display data entry/Update successful

8) Retrieve updated Strategy plan information

9) Return strategy plan information

10)Display strategy plan information

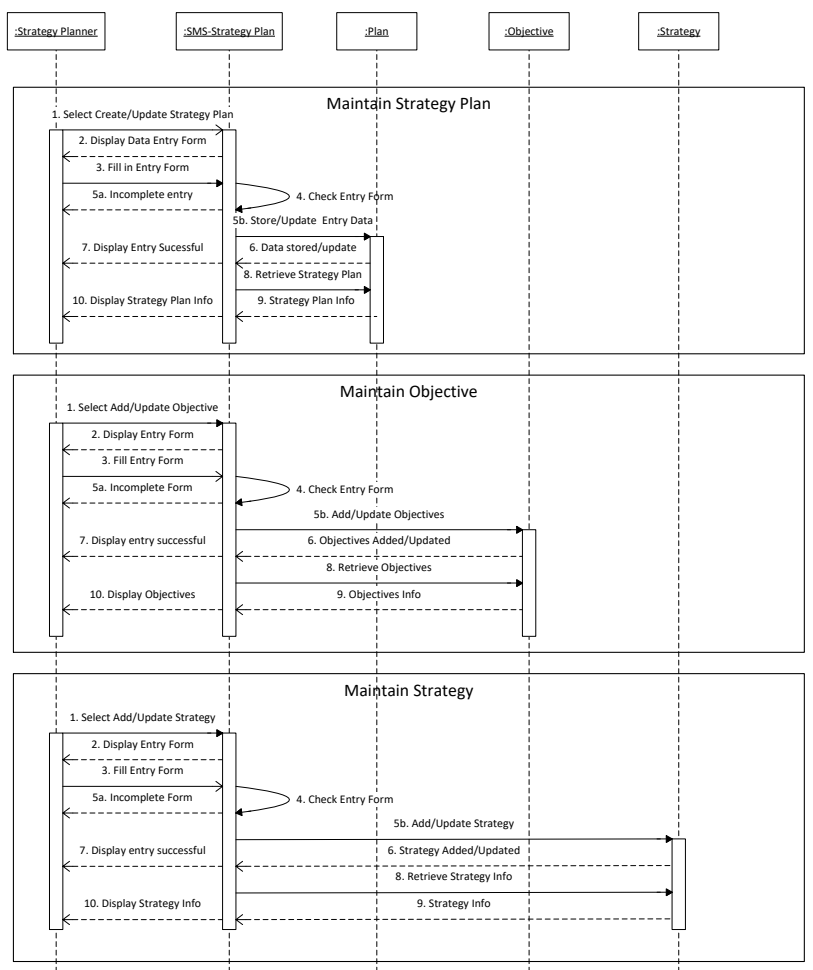

Fig. 4. Sequence diagram to manage strategy plan

The steps to maintain (add or update) the objective are as follows:

1) Select add/update objective of the Strategy Plan

2) Display data entry form to add/update objectives

3) Fill in the objectives of the strategy plan using the data entry form

4) Check and validate the information entered

5) If the data entry is incomplete, return a message "Incomplete data entry form", else proceed to store/update the data into the database
6) Return data successful stored/update into the database

7) Display data entry/update successful

8) Retrieve updated objective's information

9) Return objective's information

10)Display objectives of the strategy plan

The steps to maintain (add or update) the strategy are as follows:

1) Select add/update strategy of the Strategy Plan

2) Display data entry form to add/update strategy

3) Fill in the strategy of the strategy plan using the data entry form

4) Check and validate the information entered

5) If the data entry is incomplete, return a message "Incomplete data entry form", else proceed to store/update the data into the database

6) Return data successful stored/updated into the database

7) Display data entry/update successful

8) Retrieve updated strategy's information

9) Return strategy's information

10)Display strategies of the strategy plan

- Manage Strategy Implementation Plan

The program manager will be responsible to manage the strategy implementation plan to execute the strategy plan. The processes to manage the strategy implementation plan are: to maintain (create or update) strategy implementation plan, to maintain (add or update) program, and to maintain (add or update) project. As depicted in Fig. 5, the manage strategy implementation plan sequence diagram consists of maintain strategy implementation plan, maintain program and maintain project.

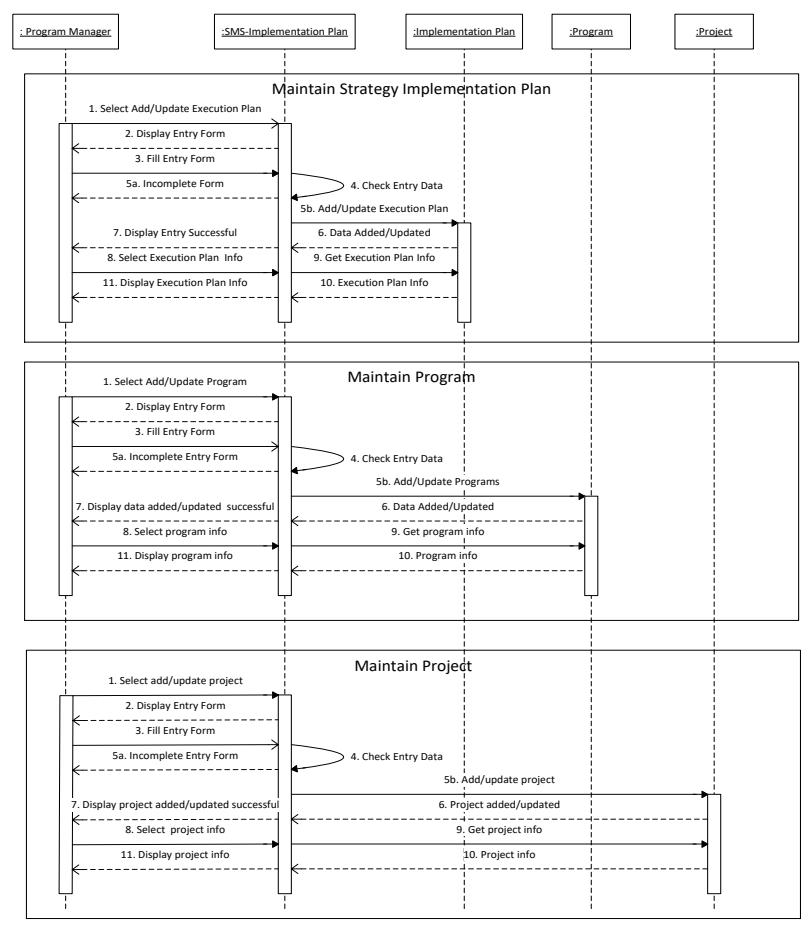

Fig. 5. Sequence diagram to manage strategy implementation plan 
The steps to maintain (create or update) the strategy implementation plan are as follows: plan

1) Select create or update the strategy implementation

2) Display data entry form to create or update the strategy implementation plan

3) Fill in the strategy implementation plan information using the data entry form

4) Check and validate the information entered

5) If the data entry is incomplete, return a message "Incomplete data entry form", else proceed to store the data into the database

6) Return data successful stored or update into the database

7) Display data entry or update successful

8) Retrieve strategy implementation plan information

9) Return strategy implementation plan information

10)Display strategy implementation plan information

The steps to maintain (add or update) program of the strategy implementation plan are as follows:

1) Select add or update program of the strategy implementation plan

2) Display data entry form to add/update programs

3) Fill in the program of the strategy implementation plan using the data entry form

4) Check and validate the information entered

5) If the data entry is incomplete, return a message "Incomplete data entry form", else proceed to store or update the data into the database

6) Return data successful stored or updated into the database

7) Display data entry successful

8) Retrieve the program information

9) Return program information

10)Display programs of the strategy implementation plan

The steps to maintain (add or update) project of the strategy implementation plan are as follows:

1) Select add/update project of the strategy implementation plan

2) Display data entry form to add/update project

3) Fill in the project of the strategy implementation plan using the data entry form

4) Check and validate the information entered

5) If the data entry is incomplete, return a message "Incomplete data entry form", else proceed to store the data into the database

6) Return data successful stored into the database

7) Display data entry successful

8) Retrieve the project information

9) Return project information

10)Display projects of the strategy implementation plan

- Manage Project Plan

The project manager is responsible to manage the project plan. The processes of manage project plan are to maintain (create or update) project plan, maintain (add or update) project information, and maintain (add and update) project performance. The sequence diagram to manage project plan is depicted in Fig. 6.

The steps to maintain (create or update) the project plan are as the follows:

1) Select create or update the project plan

2) Display data entry form to create or update the project plan

3) Fill in the project plan information using the data entry form. The project plan information includes the activities, resources, and timeline.

4) Check and validate the information entered

5) If the data entry is incomplete, return a message "Incomplete data entry form", else proceed to store or update the data into the database

6) Return data successful stored or updated into the database

7) Display data entry successful

8) Select display project plan

9) Retrieve project plan information

10) Return project plan information

11)Display project plan information

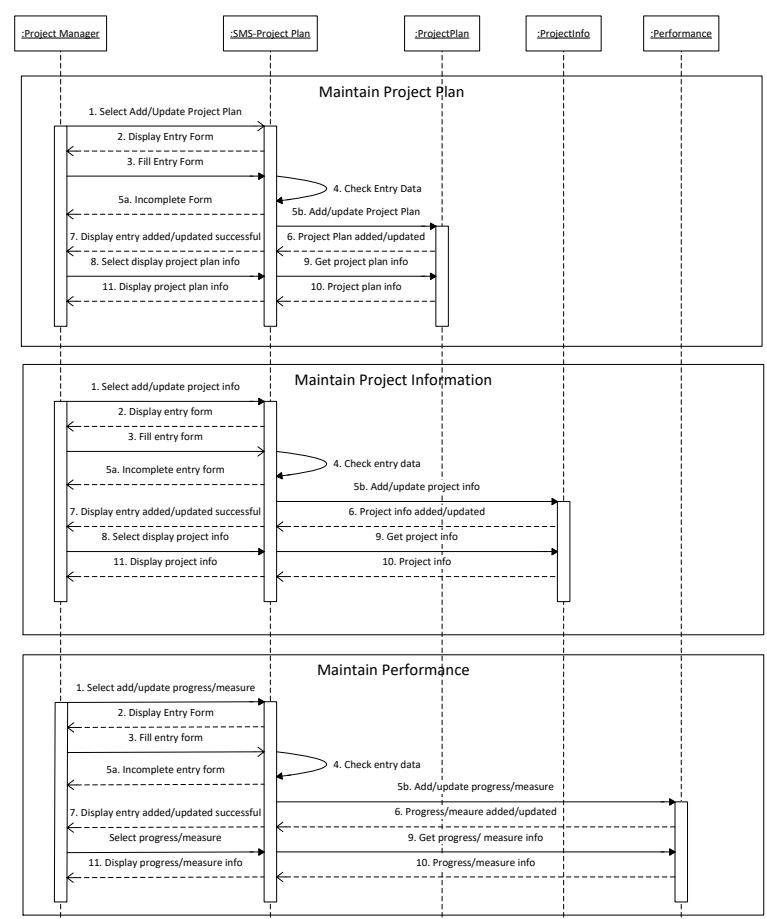

Fig. 6. Sequence diagram to manage project plan

The steps to maintain (add or update) project information are as follows:

1) Select add or update project information of the Project Plan

2) Display data entry form to add or update project information 
3) Fill in the project information of the project plan using the data entry form

4) Check and validate the information entered

5) If the data entry is incomplete, return a message "Incomplete data entry form", else proceed to store or update the data into the database

6) Return data successful stored or updated into the database

7) Display data entry successful

8) Retrieve the project information

9) Return project information

10)Display project information of the project plan

The steps to maintain (add or update) project performance:

1) Select add or update project progress or project performance measure of the project plan

2) Display data entry form to add or update project progress or project performance measure

3) Fill in the project progress or project performance measure of the project plan using the data entry form

4) Check and validate the information entered

5) If the data entry is incomplete, return a message "Incomplete data entry form", else proceed to store or update the data into the database

6) Return data successful stored or updated into the database

7) Display data entry added or updated successful

8) Select display project progress or performance measure

9) Retrieve the project progress or performance measure information

10)Return project progress or performance measure information

11)Display project progress or project performance measure of the project plan

- Monitor Strategy Planning and Implementation

The University's Council will be responsible to monitor and control the progress of the strategy planning and implementation. The processes of the monitor strategy planning and implementation are to monitor strategy plan, to monitor strategy implementation plan, to monitor project plan, and to monitor projects performance. The sequence diagram to monitor plan strategy planning and implementation is depicted in Fig. 7.

The steps to monitor strategy plan are as follows:

1) Display strategy plan's list

2) Select strategy plan

3) Get strategy plan information

4) Return strategy plan information

5) Display strategy plan information for the selected strategy plan follows:

The steps to monitor strategy implementation plan are as

1) Display strategy implementation plan's list

2) Select strategy implementation plan

3) Get strategy implementation plan information
4) Return strategy implementation plan information

5) Display selected strategy implementation plan information

The steps to monitor project plan are as the following:

1) Display project's list

2) Select project

3) Get project plan information

4) Return project plan information

5) Display selected project plan information

The steps to monitor program performance are as follows:

1) Display program's list

2) Select program

3) Get program's projects

4) Return program's project

5) Get program projects' performance information

6) Return program projects' performance information

7) Compute program's performance

8) Display selected program performance information The steps to monitor project performance are as follows:

1) Display project's list

2) Select project

3) Get project performance information

4) Return project performance information

5) Compute project performance

6) Display selected project performance information

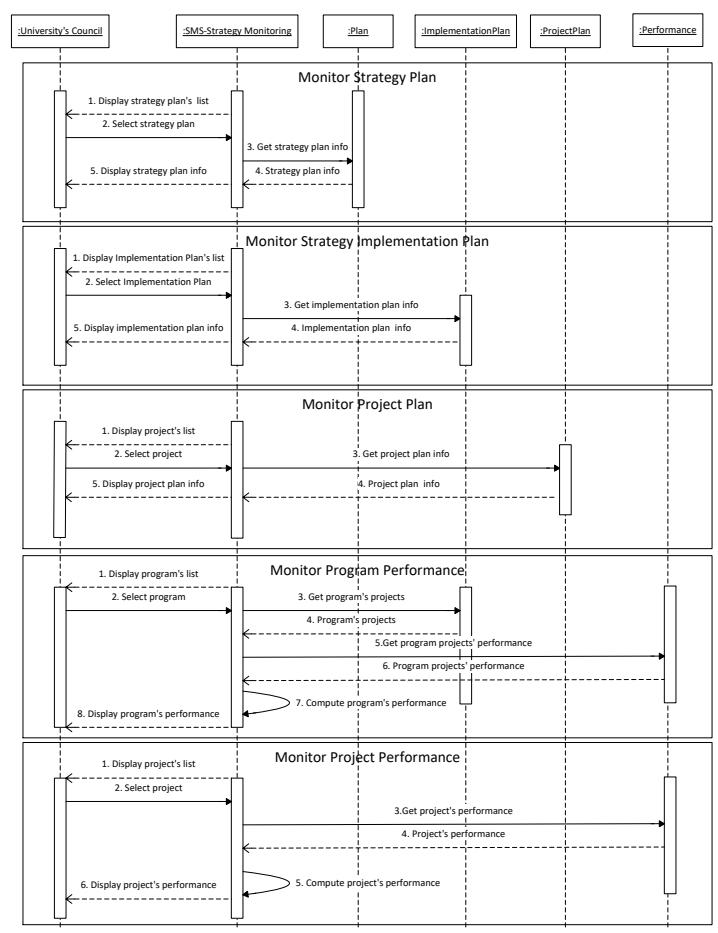

Fig. 7. Sequence diagram for monitoring strategy planning and implementation

- Evaluate Performance

The University's Council will need to evaluate program and project performance. The sequence diagram to evaluate 
performance is depicted in Fig. 8. The steps to evaluate program performance are as follows:

1) Display program's list

2) Select program

3) Get program's projects

4) Return program's projects

5) Get the projects' performance measures for the selected program

6) Return projects' performance measures

7) Display projects' performance measures

8) Evaluate the program's performance

9) Store the program's performance evaluation

10)Return program's performance evaluation stored

11)Display selected program's performance evaluation stored successful

The steps to evaluate project performance are as follows:

1) Display project's list

2) Select project

3) Get the project's performance measures for the selected project

4) Return project's performance measure

5) Display project's performance measure

6) Evaluate the project's performance

7) Store the project's performance evaluation

8) Return project's performance evaluation added

9) Display selected project's performance evaluation added successful

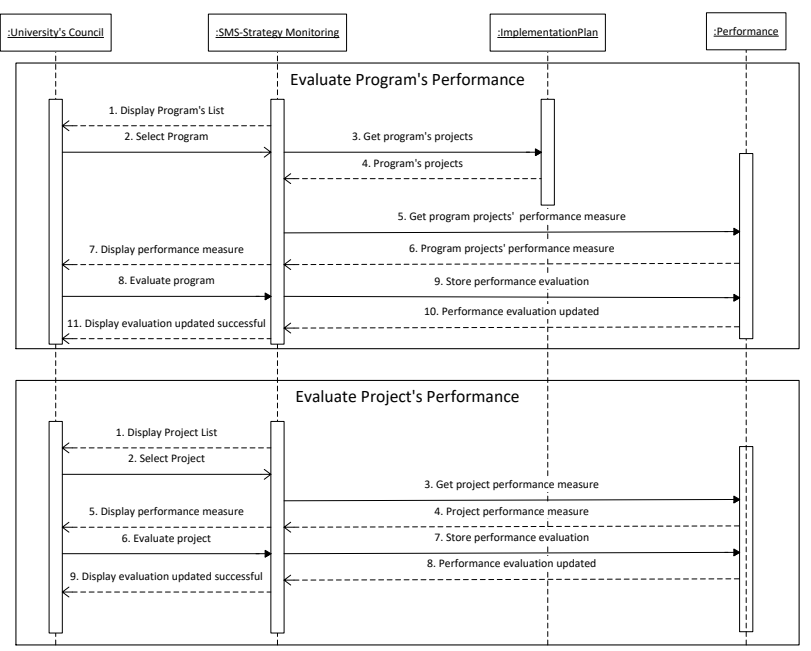

Fig. 8. Sequence diagram to evaluate performance

\section{- Generate Reports}

The Strategy Planner, Program Manager, Project Manager and University's Council will need to generate reports. The sequence diagram to generate reports is depicted in Fig. 9.

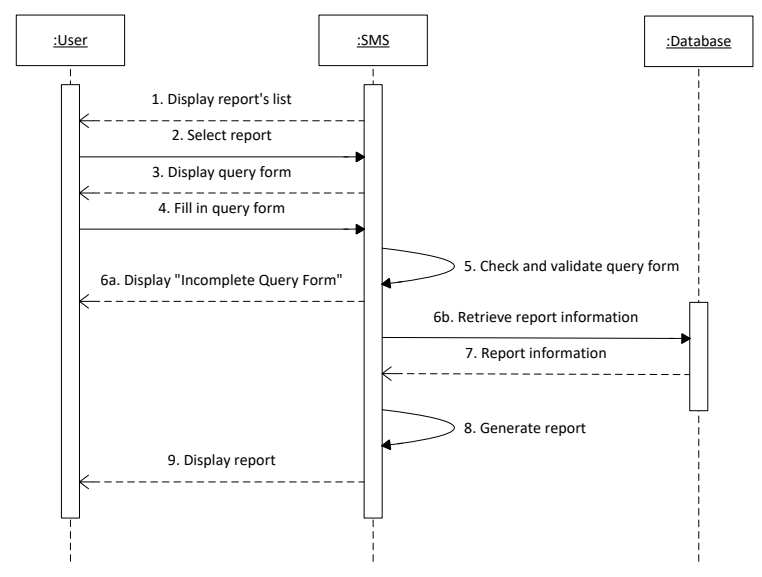

Fig. 9. Sequence diagram to generate reports

The steps to generate reports are as follows:

1) Display list of reports

2) Select report

3) Display query form to generate report

4) Fill in the required information using the query form

5) Check and validate the information entered

6) If the data entry is incomplete, return a message "Incomplete query form", else proceed to retrieve the required information to generate the report from the database

7) Return the required information to generate report

8) Generate report

9) Display selected report information

\section{CONCLUSIONS}

The paper has presented an analysis and design for a proposed Strategic Management System for NBU. The design is based on UML which provides the Use Case diagram, Class diagram, and Sequence diagram of the proposed SMS. The Use Case diagram is used to define the main actors and the functionalities of the SMS. Class diagram is used to define the objects or classes with their attributes and operations for SMS. Sequence diagram is used to define the processes for each of the functionalities of SMS. The design of the SMS will be used as the basis to develop the SMS which will then be used to formulate, implement, monitor and control appropriate university's strategy plan to support on strategic-decision making for the university.

\section{ACKNOWLEDGMENT}

The author would like to acknowledge the Northern Border University (NBU) for the financial support under the Deanship of Scientific Research (Research Project No.: 7243-SCI-20171-8-F). The author also would like to thank those who assisted along the research progress.

\section{REFERENCES}

[1] F. Alamsjah, "Key success factors in implementing strategy: middlelevel management' perspective", Procedia Social and Behavioral Sciences, 24, 2011, pp.1444-1450

[2] M. K. Allio, "A short, practical guide to implementing strategy", Journal of Business Strategy, 26, 2005, pp.12-21 
[3] S. M. Al-Ghamdi, "Obstacles to successful implementation of strategic decisions: The British experience", European Business Review, 98(6), 1998, pp.322-327

[4] M. Beer and R. A. Eisenstat, "The six silent killers of strategy implementation", Sloan Management Review, 29, 2000

[5] Al Bento, R. Bento, and L. F. White, "Strategic Performance Management Systems: Impact on Business Results“, The Journal of Computer Information Systems, Stillwater Vol. 54, Iss. 3, pp. 25-33, Spring 2014

[6] S. Bungay, and M. Goold, “Creating a strategic control system”, Long Range Planning, Vol. 24, Issue 3, pp. 32-39, , June 1991

[7] T. Cater and D. Pucko, "Factors of effective strategy implementation: empirical evidence from Slovenian business practice", Journal for East European Management Studies, 3, 2010

[8] Don Collier, "Strategic Planning Systems Design and Operation", Journal of Business Strategy, Vol. 1 Issue: 2, 1980, pp.76-77

[9] R. W. Cotterill, "The Design and Impact of Strategic Management Information Systems", American journal of agricultural economics, Vol. 70 Issue: 2, 1988, pp. 475

[10] F. R. David, "Strategic Management Concept and Cases (eight editions)", Prentice Hall: New Jersey, 2010

[11] B. Faure and L. Rouleau, "The strategic competence of accountants and middle management in budget making", Accounting, Organizations and Society, 36, 2011, pp.167-182

[12] P. C.Flood, T. Dromgole, S. J. Carroll, and L. Gorman (Eds), "Managing Strategy implementation: an Organizational Behavior Perspective". Oxford: Blackwell, 2000

[13] Kyung II Ghymn and R. William, "Design of a strategic planning management information system“, Omega, Volume 4, Issue 5

[14] L.G.Hrebiniak, "Obstacles to effective strategy implementation", Organizational Dynamics, 35(1), 2016, pp.12-31

[15] C. Jooste and B. Fourie, "The role of strategic leadership in effective strategy implementation: Perceptions of South African strategic leaders", Southern African Business Review, 13(3), 2009.

[16] R. S. Kaplan and D.P. Norton "The strategy-focused organization: how balanced scorecard companies thrive in the new business environment", MA: Harvard Business School Press, 2001
[17] R. S. Kaplan and D.P. Norton, "Strategy maps: turning tangible assets into tangible results", MA: Harvard Business School Press, 2004

[18] Akram Jalal Karim, "The Significant of Management Information Systems for Enhancing Strategic and Tactical Planning", Journal of Information Systems and Technology Management : JISTEM; Sao Paulo Vol. 8, Iss. 2, 2011, pp. 459-470.

[19] Michael Allan Lanser, "Design of a strategic information system to assist executive and management staff at Lakeshore Technical College make customer-focused program and service decisions", Nova Southeastern University, ProQuest Dissertations Publishing, 1998. 9911543.

[20] Y. Li, S. Guohui, and M.J. Eppler, "Making strategy works: a literature review on the factors influencing strategy implementation", ICA Working Paper 2, 2008

[21] M.C.Mankins and Steele, "Turning great strategy into great performance", Harvard Business Review, 83(7/8), 2005, pp. 64-72

[22] C.H. Noble and M.P. Mokwa, "Implementing marketing strategies: Developing and testing a managemential theory", Journal of Marketing, 63(October), 1999, pp.57-73.

[23] Kathy O'Sullivan, "Implementing a Strategic Planning and Management System at a Private Higher Education Institution in the Middle East: A Balanced Score Card or a Bewildering State of Confusion? “, Journal of Management education (Champaign, Ill.), Vol. 16 Issue 3, 2016, pp. 111

[24] J. A. Parnell, "Strategic capabilities, competitive strategy, and performance among retailer in Argentina,Peru and the United States", Management Decision, 49(1), 2011, pp.130-155

[25] B. Ramaseshan, A. Ishak, and F.K. Rabbanee, "The Role of marketing management' commitment and involvement in marketing strategy implementation", Journal of Strategic Marketing, 2013.

[26] A.A.Thompson and A.J. Strickland, "Strategic Management: Concepts and Cases (thirteenth edition)", New York: McGraw-Hill, 2003

[27] A. Thompson, M. Peteraf, J. Gamble, and Strickland III., "Crafting \& Executing Strategy: The Quest for Competitive Advantage: Concept and Concepts and Cases", Eighteenth (18th) Edition, 2011

[28] N. E.Wanjohi,"Strategic control systems in strategy implementation and financial performance of Bamburi Cement Limited, Kenya", School of Business, University of Nairobi, Kenya, MBA Thesis, Sept 2013 